\title{
Controle de plantas daninhas e aspectos produtivos de morangueiro sob diferentes coberturas do solo
}

\author{
Weed control and production aspects of strawberry in different ground covers
}

\section{Jeferson Tonin ${ }^{1}$, José Tobias Marks Machado ${ }^{1 *}$, Lisiane Sobucki², Jorge Atilio Benati², Bruna Rohrig ${ }^{2}$ e Evandro Pedro Schneider ${ }^{2}$}

Recebido em 26/07/2016 / Aceito em 26/09/2016

\section{RESUMO}

Este trabalho teve o objetivo de avaliar a produtividade do morangueiro em função de diferentes coberturas de solo e a efetividade destas sobre o controle de plantas daninhas, em sistema orgânico de produção. $\mathrm{O}$ experimento foi conduzido em área da Universidade Federal da Fronteira Sul - UFFS, Campus Cerro Largo. Utilizou-se delineamento de blocos ao acaso com seis blocos. Cada parcela foi constituída por dez plantas da cultivar Aromas, dispostas em quatro linhas intercaladas, distanciadas em 0,30 metros. Os tratamentos utilizados foram plantas inteiras de Capim Sudão (Sorghum sudanense), maravalha, acícula de pinus (Pinus elliottii), polietileno preto e solo descoberto. Para a determinação dos aspectos produtivos foram avaliadas a produtividade em massa, o número e o tamanho dos pseudofrutos. A efetividade de controle das plantas daninhas pelas diferentes coberturas foi determinada através da massa seca das plantas coletadas mensalmente. Com exceção da cobertura com Capim Sudão, todos os demais tratamentos se equiparam, estatisticamente, nos aspectos produtivos. A cobertura com polietileno preto apresentou maior controle sobre plantas daninhas.

PALAVRAS-CHAVE: Fragaria $X$ ananassa, mulching, produção de base ecológica.

\footnotetext{
ABSTRACT

The objective was to evaluate strawberry productivity under different soil cover, as well as its effectiveness on the weed control in an organic production system. The experiment was conducted in the Universidade

${ }^{1}$ Universidade Federal do Rio Grande do Sul, Porto Alegre, RS, Brasil.

${ }^{2}$ Universidade Federal da Fronteira Sul, Cerro Largo, RS, Brasil.

*Autor para correspondência <tobias.machado@hotmail.com>
}

Federal da Fronteira Sul - UFFS, campus Cerro Largo. The random blocks delineation with 6 blocks was used. The units were designed using 10 "aromas" cultivar plants, planted in 4 interspersed lines each $0,3 \mathrm{~m}$ apart. The treatments used were whole plants of Sudan grass (Sorghum sudanense), shavings, acicula of Pinus (Pinus elliottii), black polyethylene and uncovered soil. To determine the productive aspects, the mass production, number and size of fruit were evaluated. The effectiveness of the weed control under different soil cover was determined through the dry weed mass collected monthly. With the exception of the sudan grass, all the other treatments statistically matched the productive aspects. The black polyethylene cover presented better weed control.

KEYWORDS: Fragaria $X$ ananassa, mulching, ecologic production base.

\section{INTRODUÇÃO}

A cultura do morangueiro é, no país, uma das espécies de maior expressão econômica dentro do grupo das pequenas frutas, com produção estimada em 110 mil toneladas em uma área de 4.200 hectares (ANTUNES \& PERES 2013), sendo os estados de Minas Gerais, Paraná, Rio Grande do Sul e São Paulo, respectivamente, os maiores produtores da fruta (FACHINELLO et al. 2011). A grande maioria desta produção é realizada em sistema convencional, sendo que DAROLT (2008) estima que apenas 1\% de toda área é cultivada sob sistema orgânico.

Tanto no sistema convencional como no orgânico, a cobertura de solo, também conhecida como mulching, é amplamente utilizada. A cobertura de solo com polietileno é uma característica do cultivo 
que vem sendo utilizada desde os anos 1970, de forma que o principal benefício da utilização desse insumo é o controle de doenças e de plantas daninhas (GOTO 1997). O uso de cobertura de solo cria um ambiente com baixa umidade relativa, diminuindo os inóculos de doença, sendo que o não contato do fruto com o solo diminui a incidência de podridões, aumentado a qualidade das frutas (SANTOS \& MEDEIROS 2003).

Geralmente a cobertura dos canteiros é realizada com polietileno preto, no entanto, apesar dos benefícios do uso desse insumo, esse material tende a formar um microclima seco e propício ao aparecimento de ácaros, ao qual a cultura do morangueiro é bastante sensível, além de ser um insumo que aumenta os custos de produção (SANTOS \& MEDEIROS 2003). Reconhecendo isso, destaca-se a importância da busca por outras coberturas de solo para a produção de morangueiro (VALAITI et al. 2010). Os mesmos autores afirmam, porém, serem escassos os trabalhos com o intuito de avaliar o desempenho da cultura do morangueiro cultivada sobre outros materiais para cobertura de solo alternativos ao polietileno. Desse modo, avaliar cientificamente esses materiais, para que possam ser explorados e conhecidos seus efeitos sobre a cultura, bem como sua viabilidade ou não viabilidade na produção de morangueiro é necessária. FIAMETTI et al. (2010), avaliando a produtividade de morangueiro sob diferentes coberturas de solo no Paraná, observaram que maravalha e feno proporcionaram as mesmas produtividades que a cobertura com polietileno preto.

Contudo, outro ponto importante a ser observado é a eficiência destas coberturas, não apenas em aspectos de produtividade, mas sim considerando a efetividade no controle de plantas daninhas, uma vez que, embora com produtividades semelhantes, algumas coberturas podem demandar necessidade de capina dos canteiros, por exemplo. Em estudo realizado em Santa Catarina SILVA \& MUELLER (2010) avaliando a infestação de plantas daninhas e produtividade de tomate não se observou diferenças na produtividade, no entanto para ocorrência de plantas daninhas houve diferenças significativas entre os tratamentos avaliados.

A partir do exposto, objetivou-se avaliar a produção de morangueiro em função das diferentes coberturas de solo, bem como a efetividade das mesmas sobre o controle de plantas daninhas, em sistema orgânico de produção.

\section{MATERIAL E MÉTODOS}

O experimento foi implantado no dia 06/07/13, em área experimental da Universidade Federal da Fronteira Sul, Campus Cerro Largo, RS com localização de latitude $28^{\circ} 08^{\prime \prime}$ sul; longitude $54^{\circ} 44^{\prime \prime}$ oeste e altitude de 210 metros. O solo do local foi classificado como Latossolo Vermelho (SANTOS et al. 2010) e clima Cfa, segundo classificação de Köppen (KOPPEN 1931). As correções da fertilidade e pH do solo foram feitas 60 dias antes ao transplantio das mudas, através da aplicação de esterco bovino, biofertilizante super magro e calcário de conchas, em quantidades embasadas na interpretação da análise de solo.

Utilizaram-se canteiros abrigados por túneis baixos, dispostos no sentindo Leste-Oeste, providos de sistema de irrigação por gotejamento. $\mathrm{O}$ manejo adotado durante o ciclo de cultivo consistiu na retirada de folhas doentes em conjunto com aplicações de calda bordalesa, óleo de nim (Azadirachta indica) e Curamor, produto a base de calda bordalesa mais extratos vegetais (CLARO 2001). A utilização de tais produtos é assegurada pela Instrução Normativa 17, do Ministério da Agricultura Pecuária e Abastecimento (BRASIL 2014), para sistemas de cultivo orgânico. A periodicidade de aplicação destes produtos variou de acordo com a necessidade observada durante o ciclo de cultivo.

O delineamento experimental utilizado foi de blocos ao acaso com seis repetições e dez plantas por parcela, sendo estas dispostas em quatro linhas intercaladas em formato de quincôncio, com todas as plantas distanciadas entre si em $0,3 \mathrm{~m}$. Por trataremse de coberturas de solo se optou por distanciar as parcelas experimentais em $0,5 \mathrm{~m}$ entre si, para que assim se reduzisse o efeito dos tratamentos entre as parcelas. Foram testadas cinco tratamentos como cobertura de solo, sendo estas, plantas inteiras de Capim Sudão (Sorghum sudanense), maravalha, acícula de pinus (Pinus elliottii), polietileno preto e solo descoberto. Nas unidades onde foram utilizados como tratamentos as coberturas de origem orgânica (plantas inteiras de Capim Sudão, maravalha e acícula de pinus), utilizou-se como parâmetro o uso de uma camada de $5 \mathrm{~cm}$ destas coberturas sobre o solo. Foram utilizadas mudas da cultivar Aromas provenientes do Chile.

Os parâmetros avaliados para a determinação de aspectos produtivos foram a produtividade em 
massa de frutas planta ${ }^{-1}$, em número de frutas planta ${ }^{-1}$ e o tamanho das frutas $\mathrm{em}^{-3}$. Efetuou-se a divisão da produção em frutas comerciais e não comerciais. Foram caracterizados como comerciais aqueles frustos com massa superior a 6 gramas e que não possuíam nenhum tipo de dano por ataque de pragas e/ou doenças (CEAGESP 2002). As frutas totais representaram todos aqueles produzidos durante o ciclo de cultivo sem distinção de tamanho. As colheitas iniciaram no dia 05/09/13 encerrando-se no dia 13/12/13, totalizando 29 colheitas, sendo que em média, foram efetuadas três colheitas por semana.

Logo após cada colheita todas as frutas colhidas eram pesadas, com auxílio de balança analítica, contadas e seu tamanho determinado. A medida do tamanho foi realizada através da utilização de recipiente graduado em mililitros, preenchido com água. Através do conhecimento do volume de líquido deslocado pelos frutos quando totalmente imersos, se determinou o volume das frutas $\mathrm{em}^{3}$.

Para determinar a efetividade das diferentes coberturas sobre o controle das plantas daninhas, a partir do início das colheitas mensalmente foram realizadas capinas manuais nas parcelas, onde se fazia o arranquio de todas as plantas daninhas em uma área central da unidade com tamanho de $1 \mathrm{~m}^{2}$. Nessa operação eram arrancadas as plantas daninhas emergidas sob as coberturas, sendo que em nenhum momento do ciclo foi feita a retirada das coberturas de cada unidade para a avaliação. Após a capina, as plantas coletadas eram secas em estufa a $60{ }^{\circ} \mathrm{C}$, onde permaneciam até atingir massa constate. Posteriormente determinou-se a massa seca das plantas utilizando balança analítica com precisão de três casas decimais. Foram feitas ao todo quatro avaliações, sendo que após o final do ciclo foi calculado o acumulado médio de massa seca das plantas daninhas em cada tratamento.

Os dados que se referiam à contagem de frutos em número sofreram transformação quadrática para estabilização da variância. Todos os dados referentes à massa seca de plantas daninhas presentes em cada tratamento foram transformados para porcentagem, considerando como testemunha o tratamento com "solo descoberto". Dessa forma os dados correspondentes ao "solo descoberto" se equivaleram, em todas as unidades e em todas as avaliações, a $100 \%$, sendo as porcentagens dos demais tratamentos, calculados em função deste.

A normalidade das variâncias dos dados obtidos para cada variável foram verificadas e então submetidos a análise de variância, as variáveis significativas pelo teste $\mathrm{F}(\mathrm{p} \leq 0,05)$ tiveram as médias comparadas pelo teste de Scott-Knott ao nível de 5\% de probabilidade de erro.

\section{RESULTADOS E DISCUSSÃO}

Tratando-se da produção acumulada durante todo o ciclo de cultivo, como pode ser observado na Tabela 1, houve significância estatística dos dados referentes à produção total e de frutas comercializáveis. O mesmo aconteceu para os dados relativos ao número frutas planta ${ }^{-1}$ totais e frutas comercializáveis, porém não foi encontrada significância estatística para os dados que se referiram ao tamanho dos frutos.

Quanto à produção total em frutas planta-1, as maiores produções encontradas foram para os tratamentos maravalha, solo descoberto, acícula de pinus e polietileno preto, os quais não se diferenciaram estatisticamente entre si, sendo que o tratamento capim sudão obteve o menor valor e diferenciouse dos demais. Esta mesma situação foi observada quando avaliado apenas os frutos comercializáveis, onde estes quatro tratamentos se diferenciaram da cobertura com capim sudão.

A alta massa seca de plantas daninhas em todo o ciclo (Figura 1) pode explicar a menor produção alcançada pela cobertura de capim sudão, uma vez que as plantas daninhas são um dos principais gargalos da produção de hortaliças em sistema orgânico, especialmente por serem culturas de ciclo curto e, na maioria das vezes, de espaçamento reduzido (SEDIYAMA et al. 2014).

Em Chapecó, SC, um estudo (BRUGNARA et al. 2011) avaliando três cultivares de dia curto sobre dois tipos de cobertura de solo, sendo estas polietileno preto e acículas de pinus, em sistema de produção orgânico, não apontou influência destas coberturas de solo sobre a produtividade total e comercial de morangos, assim como observado neste trabalho. No entanto, os resultados encontrados no presente trabalho diferem do experimento conduzido em sistema convencional por VAILATI \& SALLES (2010), que ao avaliarem polietilieno preto, acícula de pinus, maravalha e solo descoberto, observaram que a cobertura com polietileno preto se diferenciou em termos de produção dos tratamentos com solo descoberto e cobertura com maravalha, de modo que o tratamento composto pela cobertura com polietileno 
Tabela 1 - Produção total e comercial de morangos gramas planta ${ }^{-1}$, número total e comercial de frutas planta ${ }^{-1} \mathrm{e}$ tamanho médio das frutas na produção total e comercial $\mathrm{em} \mathrm{cm}^{-3}$, em diferentes sistemas de cobertura do solo.

Table 1 - Production and commercial total of grams planta strawberries ${ }^{1}$, total and commercial number of plant fruits ${ }^{-1}$ and average size of fruits in total and commercial production in $\mathrm{cm}^{-3}$, in different soil cover systems.

\begin{tabular}{lcccccc}
\hline \multirow{2}{*}{ Tratamentos } & $\begin{array}{c}\text { Produção } \\
\text { Total } \\
\left(\mathrm{g} \mathrm{planta}^{-1}\right)\end{array}$ & $\begin{array}{c}\text { Produção } \\
\text { comercial } \\
\left(\mathrm{g} \mathrm{planta}^{-1}\right)\end{array}$ & $\begin{array}{c}\text { Número Total } \\
\text { de frutas por } \\
\text { planta }\end{array}$ & $\begin{array}{c}\text { Número de frutas } \\
\text { comerciais por } \\
\text { planta }\end{array}$ & $\begin{array}{c}\text { Tamanho médio } \\
\text { das frutas } \\
\left(\mathrm{cm}^{3}\right)^{\mathrm{ns}}\end{array}$ & $\begin{array}{c}\text { Tamanho das } \\
\text { frutas comerciais } \\
\left(\mathrm{cm}^{3}\right)^{\mathrm{ns}}\end{array}$ \\
\hline Maravalha & $267,18 \mathrm{a}^{*}$ & $254,823 \mathrm{a}$ & $23,32 \mathrm{a}$ & $20,30 \mathrm{a}$ & 11,68 & 12,76 \\
Solo Descoberto & $260,13 \mathrm{a}$ & $248,33 \mathrm{a}$ & $23,28 \mathrm{a}$ & $20,58 \mathrm{a}$ & 12,4 & 13,18 \\
Acícula de Pinus & $256,42 \mathrm{a}$ & $244,67 \mathrm{a}$ & $22,04 \mathrm{a}$ & $19,11 \mathrm{a}$ & 11,62 & 12,78 \\
Polietileno Preto & $255,87 \mathrm{a}$ & $243,06 \mathrm{a}$ & $25,79 \mathrm{a}$ & $22,20 \mathrm{a}$ & 11,56 & 12,82 \\
Capim Sudão & $152,75 \mathrm{~b}$ & $143,76 \mathrm{~b}$ & $14,78 \mathrm{~b}$ & $12,54 \mathrm{~b}$ & 10,69 & 11,89 \\
\hline \multicolumn{1}{c}{ CV (\%) } & 12,18 & 13,21 & 7,04 & 8,32 & 9,26 & 9,34
\end{tabular}

*Médias seguidas por mesma letra na coluna, não diferem entre si pelo teste Scott-Knott a 5\% de probabilidade.

${ }^{\text {ns }}$ Dados que não apresentaram significância estatística.

produziu mais do que os demais tratamentos.

Para o número total de frutos, o tratamento utilizando polietileno preto possui a maior média dentre os tratamentos, mas não difere estatisticamente das coberturas com acícula de pinus, maravalha e solo descoberto. Para o número de frutos comercias se observou a mesma tendência onde a cobertura com capim sudão se diferenciou estatisticamente dos demais tratamentos com o menor número de frutas acumulado.

Em experimento realizado no Paraná (FIAMETTI et al. 2010) os autores testaram maravalha, polietileno preto, solo descoberto e outras três coberturas não testadas aqui, de forma que encontrou-se maior produção em número de frutas comercializáveis para a cobertura com maravalha, diferenciando-se do tratamento com solo descoberto e polietileno preto. É interessante lembrar, porém, que os resultados referentes ao número total de frutas encontrados nesse trabalho para a cobertura com polietileno preto e solo descoberto $(25,8$ e 23,3 frutas planta $^{-1}$, respectivamente) superam àqueles encontrados pelos autores (11,7 e 8,50 frutas planta $\left.{ }^{-1}\right)$. O valor enontrado para a cobertura com maravalha é semelhante ao descrito por FIAMETTI et al. (2010).

Referente à efetividade de controle dos tratamentos sobre as plantas daninhas (Figura 1), na primeira avaliação as coberturas de polietileno preto, maravalha e acícula de pinus se destacaram como os tratamentos de maior controle, equiparando-se estatisticamente. $\mathrm{O}$ tratamento de solo descoberto se diferenciou destes e do capim sudão, tendo pior eficiência. Na segunda avaliação, a cobertura com polietileno preto foi a que apresentou maior controle, se diferenciando dos demais tratamentos. Os tratamentos com maravalha e acícula de pinus não se diferenciaram entre si, porém obtiveram maior controle comparado aos tratamentos sem cobertura e capim sudão. $O$ tratamento com capim sudão se diferenciou estatisticamente dos demais tratamentos, com a menor efetividade de controle, devendo-se isso à grande incidência de plântulas do próprio capim sudão que germinaram antes dessa avaliação.

Para a terceira avaliação, todos os tratamentos se diferenciaram estatisticamente entre si, onde a cobertura com polietileno obteve resultado de controle mais satisfatório, enquanto o solo descoberto atingiu o maior nível de infestação por plantas daninhas. $\mathrm{Na}$ quarta avaliação a cobertura com polietileno, novamente apresentou maior controle, diferenciando estatisticamente dos demais tratamentos. Maravalha, acícula de pinus e solo descoberto não se diferenciaram estatisticamente entre si. Capim sudão se diferenciou de todos com o menor potencial de controle, atingindo níveis consideravelmente mais altos se comparado as demais coberturas.

Na média para todo ciclo, a cobertura com polietileno preto obteve maior controle de plantas daninhas, as coberturas com maravalha e acícula de pinus se equipararam estatisticamente, diferenciandose dos tratamentos solo descoberto e capim sudão. A cobertura com capim sudão apresentou maior 


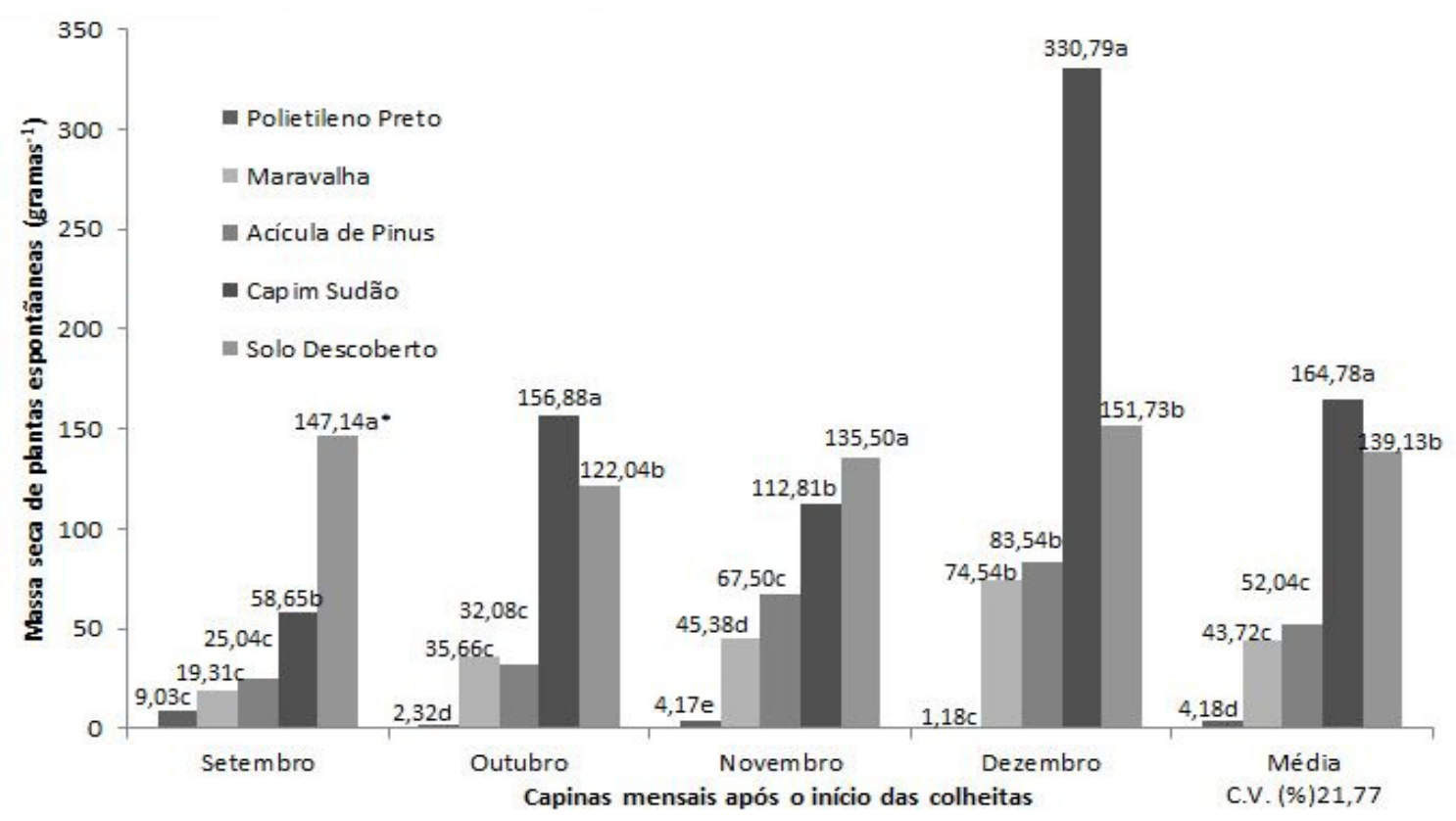

*Médias seguidas por mesma letra, não diferem entre si pelo teste Scott-Knott em $5 \%$ à probabilidade.

Figura 1 - Massa seca de plantas daninhas infestantes sobre as diferentes coberturas de solo, durante o ciclo de cultivo e na média total do ciclo.

Figure 1 -Dry matter of weeds infestation on the different soil cover, on the cultivation cycle and on the total average of cycle

acúmulo médio de massa seca de plantas daninhas, diferenciando-se estatisticamente.

Os resultados alcançados para a cobertura com capim sudão tanto em termos de produtividade quanto na eficácia de controle sobre plantas daninhas, deve-se ao uso da planta inteira (com a presença de sementes maduras), o que por consequência causou a emergência de plantas do próprio capim utilizado na cobertura, tornando-se as plântulas concorrentes com o morangueiro, sendo a interferência maior até mesmo se comparado com tratamento solo descoberto. Os resultados obtidos pela cobertura vegetal de capim sudão foram influenciados diretamente pelo ponto de coleta da cultura, sendo que a utilização da planta como cobertura no estádio de grão leitoso, poderia ter evitado a germinação, o qual foi fator determinante do resultado insatisfatório no controle de infestação por plantas daninhas.

As capinas mensais realizadas durante o ciclo demonstram que em todas as avaliações e na média geral que o tratamento com solo descoberto, como esperado, apresentou produção de massa seca de plantas daninhas superior aos demais tratamentos, excetuando-se o tratamento com capim sudão. A não diferenciação em termos de produtividade $\mathrm{e}$ número de frutas, entre o tratamento polietileno preto, comparada aos tratamentos acícula de pinus, maravalha e solo descoberto pode ser explicada, para os últimos, pela capina mensal, que evitou tanto a perda de rendimento por competição entre plantas, como também pela redução da amplitude térmica do solo causada pela utilização destas coberturas (STRECK et al. 1994). No caso do tratamento com solo descoberto, possivelmente, a própria cobertura verde proveniente da população de plantas daninhas, tenha agido como cobertura termorreguladora.

Ainda que o tratamento com solo descoberto tenha atingido altos valores de massa seca de plantas daninhas mensalmente e no acumulado médio, indicando assim grande infestação, não foi identificada perda de rendimento devido a competição entre a cultura e as plantas daninhas. Cabe salientar que a capina mensal possivelmente tenha evitado que o nível de competição entre as culturas e as plantas daninhas se refletisse em redução de produtividade. A época e a duração do período em que a cultura e a comunidade infestante convivem, influenciam consideravelmente a intensidade de interferência na produção (OLIVEIRA JUNIOR et al. 2011). Como o período e a intensidade da competição foi alterada pela capina, não se observou interferência na produção.

Entretanto deve ser salientado que a necessidade de capina, como forma de garantia para não interferência entre plantas daninhas e cultura 
pode ser uma prática pouco conciliável no sistema de produção de morangueiro comercial, uma vez que como salienta MADAIL et al. (2007), o cultivo se caracteriza pela alta utilização de mão de obra durante quase todo ciclo de cultivo. Além disso, uma grande parte da literatura tem apontado para resultados positivos com o uso de coberturas de solo alternativas face ao solo descoberto (SEDIYAMA et al. 2014), no entanto, geralmente estes trabalhos não utilizam em suas comparações o polietileno preto. No presente trabalho foi possível observar que, na média final, uma parte dos tratamentos difere e é superior ao tratamento com solo descoberto, por outro lado é inferior ao polietileno preto.

Dessa forma, é necessário considerar o fato de que, embora a produção por planta não tenha sido afetada pelos tratamentos (com exceção do capim sudão), a massa seca de plantas daninhas observada em cada tratamento permite concluir que a cobertura com polietileno preto representa a melhor alternativa dentre as testadas, dado que possui maior efetividade no controle das plantas daninhas e ao mesmo tempo, como se sabe, permite a obtenção de resultados produtivos interessantes, o que não acontece com outros tratamentos que, embora com bons resultados de produção, demandam bastante mão-de-obra no controle de plantas daninhas.

\section{CONCLUSÃO}

As coberturas com acícula de pinus, maravalha, solo descoberto, quando feita capina mensal para a retirada de plantas daninhas proporcionam desempenho produtivo, em gramas planta ${ }^{-1}$ e número de frutos planta $^{-1}$, equivalentes ao produzido com a utilização de polietileno preto.

Quanto a efetividade do controle de plantas daninhas, nenhuma cobertura se equipara a cobertura com polietileno preto, sendo as coberturas com maravalha e acícula de pinus são as que mais se aproximam da efetividade de controle do uso. Porém, considerando-se o fato de o morangueiro ser um cultivo altamente intensivo em mão de obra, nenhuma cobertura alternativa pesquisada apresenta efetividade de controle de plantas daninhas.

\section{REFERÊNCIAS}

ANTUNES LEC \& PERES N. 2013. Strawberry Production in Brazil and South America. International Journal of Fruit Science 13: 156-161.
BRASIL. 2014. Decreto $\mathrm{n}^{\circ} 6.323$, de 27 de dezembro de 2007. Disponível em: http://www.agricultura.gov.br/ arq_editor/file/Desenvolvimento_Sustentavel/Organicos/ Legislacao/Nacional/Decreto_n_06_323_de_27-12-2007. pdf. Acesso em: 20 jul. 2016.

BRUGNARA EC et al. 2011. Produção Orgânica de Diferentes Cultivares de Morangueiro Cultivados em Solo Coberto com Acículas de Pinos e Plástico Preto na Região de Chapecó, SC. Boletim de pesquisa e desenvolvimento. Pelotas: Embrapa Clima Temperado. 20p. (Boletim Técnico 133).

CEAGESP - Companhia de Entrepostos e Armazéns Gerais de São Paulo. 2002. Normas de classificação de morango. São Paulo: CQH/CEAGESP. 6p. (Documento, 22).

CLARO SA. 2001. Referenciais tecnológicos para a agricultura familiar ecológica: a experiência da Região Centro-Serra do Rio Grande do Sul. EMATER/RSASCAR. 250p.

DAROLT MR. 2008. Morango orgânico: opção sustentável para o setor. Revista Campo \& Negócios 34: 58-61.

FACHINELLO JC et al. 2011. Situação e perspectivas da fruticultura de clima temperado no Brasil. Revista Brasileira de Fruticultura 33: 109-120.

FIAMETTI MS et al. 2010. Produtividade do morango cultivado sobre diferentes Coberturas do solo, no oeste do Paraná. In: Encontro Anual de Iniciação Científica. Resumos... Curitiba: UFPR. 4p.

GOTO R. 1997. Plasticultura nos trópicos: uma avaliação técnico-econômica. Horticultura Brasileira 15: 163-165.

KOPPEN W. 1931. Grundriss der Klimakunde. Berlin: Walter de Gruyter. 390p.

MADAIL JCM et al. 2007. Avaliação econômica dos sistemas de produção de morango: convencional, integrado e orgânico. Comunicado Técnico da Embrapa Clima Temperado.Pelotas. $4 \mathrm{p}$.

OLIVEIRA JUNIOR RS et al. 2011. Biologia e manejo de plantas daninhas. Curitiba: Omnipax. 348p.

SANTOS AM \& MEDEIROS ARM. 2003. Morango: produção. Frutas do Brasil, Embrapa Clima Temperado. p.24-30.

SANTOS HG et al. 2010. Sistema brasileiro de classificação de solos. 2.ed. Brasília: Embrapa Solos. 306p.

SEDIYAMA MAN et al. 2014. Cultivo de hortaliças no sistema orgânico. Revista Ceres 61: 829-837.

SILVA L \& MUELLER S. 2010. Avaliação de coberturas vegetais no solo sobre a incidência de plantas daninhas e na produtividade de tomate. Revista de Divulgação Científica 17: 12-19.

STRECK NA et al. 1994. Modificações físicas causadas pelo mulching. Revista Brasileira de Agrometeorologia 2: 131-142.

VAILATI T \& SALLES RFM. 2010. Rendimento e qualidade de frutos de morangueiro sob diferentes coberturas de solo. Revista Acadêmica: Ciências Agrárias e Ambientais 8: 29-37. 